\title{
Cardiometabolic risk in young adults from northern Mexico: Revisiting body mass index and waist-circumference as predictors
}

\author{
Abraham Wall-Medrano ${ }^{1}$, Arnulfo Ramos-Jiménez ${ }^{1 *}$, Rosa P. Hernandez-Torres ${ }^{2}$, Rafael Villalobos-Molina ${ }^{3,4}$, \\ Diana C. Tapia-Pancardo ${ }^{3}$, J. Rafael Jiménez-Flores ${ }^{3,4}$, A. René Méndez-Cruz ${ }^{3,4}$, Miguel Murguía-Romero ${ }^{3,4}$, \\ Itzell A. Gallardo-Ortíz ${ }^{3}$ and René Urquídez-Romero ${ }^{1}$
}

\begin{abstract}
Background: A body mass index (BMI) $\geq 30 \mathrm{~kg} / \mathrm{m}^{2}$ and a waist circumference (WC) $\geq 80 \mathrm{~cm}$ in women (WCF) or $\geq 90$ $\mathrm{cm}$ in men (WCM) are reference cardiometabolic risk markers (CMM) for Mexicans adults. However, their reliability to predict other CMM (index tests) in young Mexicans has not been studied in depth.

Methods: A cross-sectional descriptive study evaluating several anthropometric, physiological and biochemical CMM from 295 young Mexicans was performed. Sensitivity (Se), specificity (Sp) and Youden's index ( $)$ of reference BMI/WC cutoffs toward other CMM $(n=14)$ were obtained and their most reliable cutoffs were further calculated at Jmax.

Results: Prevalence, incidence and magnitude of most CMM increased along the BMI range $(p<0.01)$. BMl explained $81 \%$ of WC's variance [Se (97\%), Sp (71\%), J (68\%), Jmax (86 \%), BMl $=30 \mathrm{~kg} / \mathrm{m}^{2}$ ] and 4-50 \% of other CMM. The five most prevalent $(\geq 71 \%) C M M$ in obese subjects were high WC, low HDL-C, and three insulin-related CMM [Fasting insulin, HOMA-IR, and QUICKI]. For a BMI = $30 \mathrm{~kg} / \mathrm{m}^{2}$, J ranged from $16 \%(\mathrm{HDL}-\mathrm{C} / \mathrm{LDL}-\mathrm{C})$ to $68 \%$ (WC), being moderately reliable (Jmax $=61-67)$ to predict high uric acid (UA), metabolic syndrome (MetS) and the hypertriglyceridemic-waist phenotype (HTGW). Corrected WCMNWCF were moderate-highly reliable (Jmax $=66-90)$ to predict HTGW, MetS, fasting glucose and UA. Most CMM were moderate-highly predicted at $27 \pm 3 \mathrm{~kg} / \mathrm{m}^{2}$ (Cl $\left.95 \%, 25-28\right), 85 \pm 5 \mathrm{~cm}$ (Cl $95 \%, 82-88$ ) and $81 \pm 6 \mathrm{~cm}(\mathrm{Cl} 95 \%, 75-87)$, for BMI, WCM and WCF, respectively.
\end{abstract}

Conclusion: BMI and WC are good predictors of several CMM in the studied population, although at different cutoffs than current reference values.

Keywords: Metabolic syndrome, Cardiometabolic risk, Body mass index, Waist circumference, Central obesity, Youden's index

\section{Background}

Mexico's epidemiological transition is advanced with a major burden coming from non-communicable chronic diseases. The fast urbanization, industrial development, technocratization and the apparent country's prosperity, have improved the Mexicans lifestyle but simultaneously

\footnotetext{
* Correspondence: aramos@uacj.mx

${ }^{1}$ Instituto de Ciencias Biomédicas, Universidad Autónoma de Ciudad Juárez, Anillo Envolvente del Pronaf y Estocolmo, Ciudad Juárez 32300, Chihuahua, México

Full list of author information is available at the end of the article
}

has diminished its health [1]. The rising adult mortality from cardiometabolic diseases (CMD), such as type 2 diabetes mellitus (T2DM) and hypertension (HTN) [2], a sudden (2014-2016) increase in their prevalence (8-12\%) and an unstoppable increment in treatment annual costs (US\$/ patient): 485 to 622 (HTN), 699 to 748 (T2DM) [3] are all indicative of the diminishing health state of the people. As if this were not enough, health inequities by region and population segments are still evident despite the government's efforts to reduce them [4-6]. Therefore, it is increasingly urgent the timely diagnosis of CMD, by applying 
highly sensitive, reliable and economical methods, in order to reduce their burden for public health.

Obesity [body mass index (BMI) $\geq 30 \mathrm{~kg} / \mathrm{m}^{2}$ ] and central adiposity [waist circumference (WC) $\geq 80 \mathrm{~cm}$ women (WCF), $\geq 90 \mathrm{~cm}$ men (WCM)] are prodromal conditions for many CMD [7, 8], including T2DM, metabolic syndrome (MetS) and cardiovascular disease (CVD). BMI and WC are more accurate than measured body fat by dual Xray absorptiometry (DEXA), being $\mathrm{WC}$ a better predictor of these CMD and other inflammatory diseases $[9,10]$. However, there are other CMD risk markers (CMM): HTN $(\geq 130 / \geq 85 \mathrm{mmHg}$ ), dyslipidemias [triacylglycerides (TAG $\geq 150 \mathrm{mg} / \mathrm{dl})$, total cholesterol $(\mathrm{TC} \geq 200 \mathrm{mg} / \mathrm{dl})$, low-density lipoprotein cholesterol (LDL-C $\geq 100 \mathrm{mg} / \mathrm{dl}$ ), and high-density lipoprotein cholesterol (HDL-C $<50 \mathrm{mg}$ / $\mathrm{dl}$ women, $<40 \mathrm{mg} / \mathrm{dl}$ men)] and high fasting glucose (FG $\geq 100 \mathrm{mg} / \mathrm{dl}$ ) and insulin ( $\mathrm{FI} \leq 14.0 \mu \mathrm{U} / \mathrm{ml}$ women, $\leq 11.0$ $\mu \mathrm{U} / \mathrm{ml}$ men $[11,12])$. Clustered CMM includes the hypertriglyceridemic-waist phenotype (HTGW), atherogenic index (TC/HDL-C, $>3.6$ women, $>4.3$ men), TAG/ HDL-C ( $>2.4$ women, $>2.9$ men), insulin resistance (IR: HOMA-IR $>2.9$ women, $>2.3$ men), and quantitative insulin sensitivity check index (QUICKI $\leq 0.33$ ) $[8,13-15]$. Also, since therapeutic lifestyle changes remain an essential modality in the clinical management of CMD, other health determinants including age ( $\geq 55 \mathrm{y}$ woman, $\geq 45 \mathrm{y}$ men), family history of CMD, smoking, sedentary lifestyle and high saturated fat intake, are also considered risk factors $[16,17]$.

International (e.g. WHO or NHBLI) and Mexican cutoffs for each CMM, including BMI and $\mathrm{WC}$, have been established so far. However, most of them are influenced by ethnicity, gender, age and the presence of comorbidities [18]. That is why, their sensitivity (Se) and specificity (Sp) changes from one population/region/ country to another $[19,20]$. As in case of age, according to the 2006 National Health \& Nutrition Survey [21] $\sim 50 \%$ of Mexican adults ( $\geq 20 \mathrm{y}$ ) had at least one altered CMM, 36.8 \% have MetS [22], and the most common CMM were low HDL-C (76.8 \%), high WC (73.6 \%) and the triad HDL-C/HTN/WC (20 \%) while high TAG (30.9\%) and the triad TAG/HTN/FG (0.5\%) ranked the lowest prevalent. According to this survey, age and location (urban/rural) have an impact on MetS prevalence but gender and socioeconomic status do not. However, 72 \% of young Mexicans (17-25 y) have at least one altered CMM, 13.4 \% have MetS, and the most prevalent CMM were low HDL-C (41.8 \%) and high WC (38.3\%) and TAG (18.5\%), and gender, age and even region modify MetS prevalence $[8,14,19]$.

Although international standardization of CMM cutoffs allows the timely comparison and monitoring of health policies worldwide, the use of age-specific cutoffs to evaluate intervention programs in Mexico should be carefully selected [23-25]. The aim of this study was to evaluate the predictive value of BMI and WC toward other CMM abnormalities in young Mexicans, using the Youden's index $(\zeta)$ for improving their specific cutoffs to achieve the highest Se and Sp (Jmax) [26, 27].

\section{Methods \\ Study design \& population}

A cross-sectional descriptive study with a randomized sampling and multivariate (in BMI) and bivariate (in WC) stratification was performed. 2683 students $(18.7 \pm 2.7 \mathrm{y}$; age range 17-38) admitted in August 2014 by the Autonomous University of Ciudad Juarez (UACJ), were considered the initial universe. UACJ matriculates $3900 \pm 500$ students every six months, all considered participants in the "Healthy University" project, a comprehensive program that fosters academic performance by improving health and quality of life of students as well as their empowerment as public health promoters [28]. The sample size was considered large enough $(11 \%)$ to detect (5\% precision) the lowest CMM (high $\mathrm{FG}=2 \%$ ) found in a preceding study [8] with a larger population $(22 \pm 5 \mathrm{y}$, $n=8144,49 \%$ women). However, as the purpose of the study was to validate BMI and WC as independent predictors of other CMM, a randomized sampling (based on the automatic selection of cases by school enrollment numbers) with a replacement strategy was performed in order to obtain proportional samples (50\% women/ $50 \%$ men) within 4 BMI groups $(n=294, n=$ 71-77 per group) with the following demographics: $50 \%$ female, $19 \pm 2 \mathrm{y}$, medium-high socioeconomic level. All students perceived themselves as healthy and no CMD was diagnosed by the assigned and trained physician.

\section{Data collection procedure}

A) Anthropometry: Height was determined to the nearest $0.1 \mathrm{~cm}$ using a mobile stadiometer (SECA 208, Birmingham, UK), with the subject's head in the Frankfurt plane. Body weight was determined to the nearest $100 \mathrm{~g}$ using a digital scale (Tanita 682, Illinois, USA). Body mass index was then calculated $\left[\mathrm{BMI}=\right.$ weight $(\mathrm{kg}) /$ height $\left.(\mathrm{m})^{2}\right]$. WC was measured to the nearest $0.1 \mathrm{~cm}$ midway between the top of the ileac crest and the bottom of the rib cage, perpendicular to the trunk long axis, using a non-stretch measuring tape. These procedures were performed as recommended by the International Society for the Advancement of Kinanthropometry (ISAK) and the WHO STEPS protocol. B) Blood pressure (BP): It was measured with a manual aneroid sphygmomanometer (Model DS44, Welch-Allyn) to the nearest $1 \mathrm{mmHg}$ in a seated position with the dominant arm resting and the palm facing upwards. The first Korotkoff sound marked the systolic (SBP) and the fifth the diastolic (DBP) blood pressure. Average readings $(n=3$, every $5 \mathrm{~min})$ were 
recorded at least $15 \mathrm{~min}$ after the participant arrival to the laboratory. C) Biochemistry: Students came to the University laboratory facilities between 7 and 10 AM after overnight fasting. Venous (antecubital) blood samples were obtained in suitable Vacutainer tubes by trained biochemists responsible for sample collection, and all analyses were performed by Grupo Diagnóstico Médico PROA, S.A. de C.V., a Mexican internationally certified and accredited reference laboratory. Blood samples were centrifuged and the supernatant was recovered and used to measure the following biochemical parameters: FG, Uric acid (UA), TAG, CT, and HDL-C (mg/dL) by automatized enzymatic-colorimetric methods with an overall intra- and inter-assay coefficients of variation $(\mathrm{CV})$ of $<5 \%$ and insulin $(\mu \mathrm{U} / \mathrm{ml})$ by ELISA; sensitivity was $0.5 \mu \mathrm{U} / \mathrm{mL}$, and $\mathrm{CV}<5 \%$. Non HDL-C, LDL-C [29], HOMA-IR [16] and QUICKI [13], were then calculated with the following equations:

$$
\begin{aligned}
& \text { Non HDL-C }=\text { TC }-(\text { HDL-C }) \\
& \text { LDL-C }=\text { TC }-(\text { HDL-C })-\text { TAG } / 5 \\
& \text { HOMA-IR }=\text { FI } * \text { FG } / 405 \\
& \text { QUICKI }=1 /[\log (\mathrm{FI})+\log (\mathrm{FG})]
\end{aligned}
$$

\section{Operational definitions}

Students were classified at risk of CMD if they had at least one altered CMM, or as healthy if they had none of them. MetS was defined according to the consensus definition (IDF/NHLBI/AHA/WHF/IAS/IASO) [30] if they met at least 3 of the following traits or conditions: WC (WCF $\geq 80 \mathrm{~cm}$, WCM $\geq 90 \mathrm{~cm})$, TAG $(\geq 150 \mathrm{mg} / \mathrm{dl}$ ), HDL-C $(<50 \mathrm{mg} / \mathrm{dl}$ women, $<40 \mathrm{mg} / \mathrm{dl}$ men), HTN $(\geq 130 / \geq 85 \mathrm{mmHg})$ and FG $(\geq 100 \mathrm{mg} / \mathrm{dl})$. Hyperuricemia (UA) was defined here as UA $(\mathrm{mg} / \mathrm{dl})>7.0$ women, $>8.0$ men [31].

\section{Statistical analysis}

All statistical analyses were performed with SPSS statistical software package version 22.0 (SPSS Inc., Chicago, IL, USA). All anthropometric, physiological and biochemical parameters were evaluated in stratified groups: A) By BMI $[n=71-77$ each: $<18.5$ (underweight), 18.524.9 (normal), $25.0-29.9$ (overweight) and $\geq 30.0 \mathrm{~kg} / \mathrm{m}^{2}$ (obese)], B) In two (normal \& high) WCF/WCM groups, Goodness-of-fit $\left(\mathrm{R}^{2}\right)$ between BMI and other CMM was performed, adjusting data to the best regression curve possible (linear, quadratic, cubic, exponential or power). The reliability of reference standard BMI (25 and 30 $\mathrm{kg} / \mathrm{m}^{2}$ ), WCF $\geq 80 \mathrm{~cm}$ and $W C M \geq 90 \mathrm{~cm}$ cutoffs as independent predictors of other CMM abnormalities, was analyzed by their sensitivity (Se, low false negatives) and specificity ( $\mathrm{Sp}$, low false positives) using crosstabs [14], receiver operating characteristic (ROC) curves, and Youden's Index (J) [26]. $J$ (Eq. 5) is defined at all points of a ROC-curve and its maximum value (Jmax =highest Se and $\mathrm{Sp}$ ) is used as a criterion for selecting the optimum or most reliable cutoff (Fig. 1).

$$
\begin{aligned}
J= & \text { Sensitivity }(\mathrm{Se}, \%) \\
& + \text { Specificity }(\mathrm{Sp}, \%)-100
\end{aligned}
$$

\section{Results}

CMM values (mean $\pm \mathrm{SD}$ ) increased across BMI categories ( $p \leq 0.01$, Table 1$)$. WC, the 1 st and 4 th most prevalent
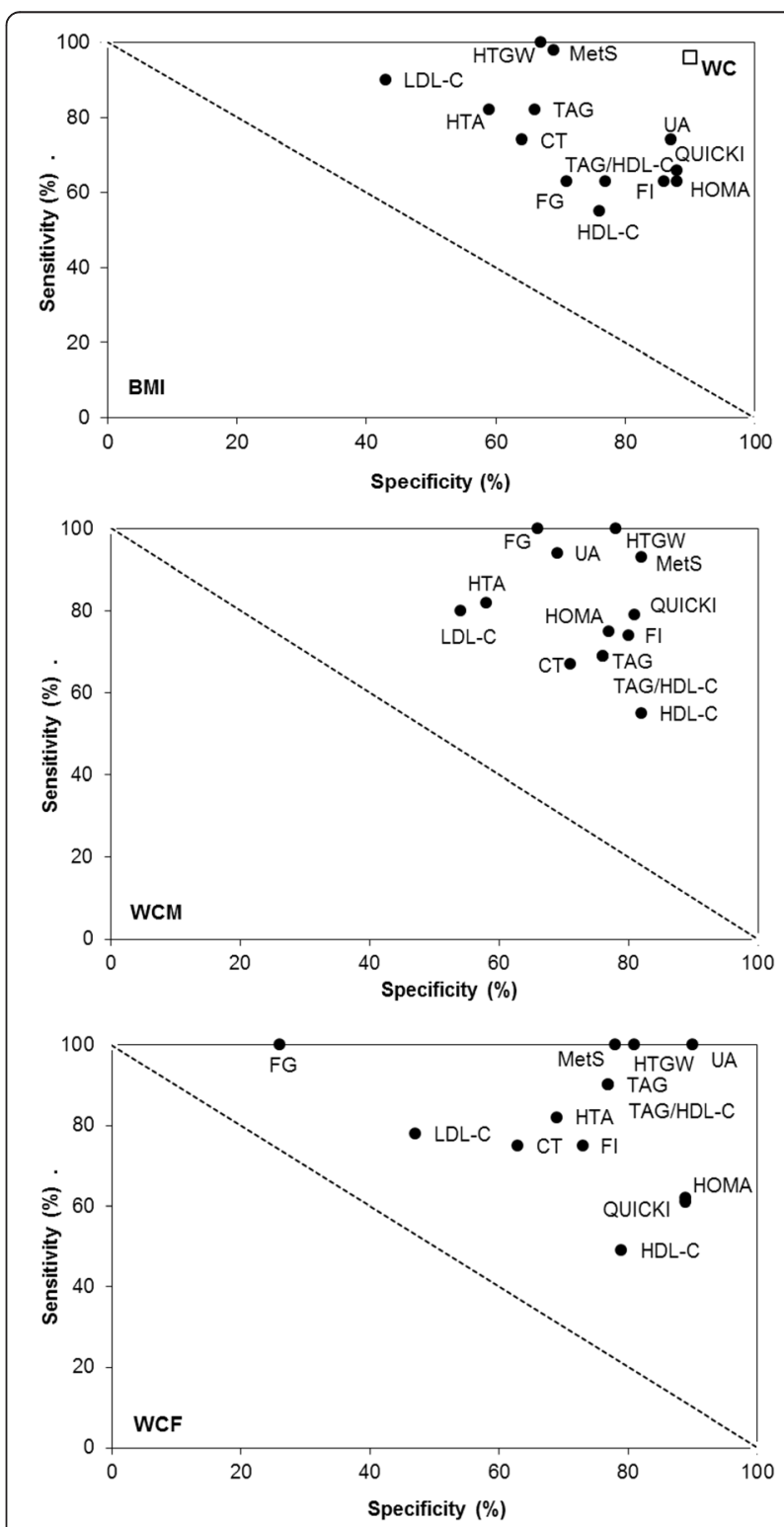

Fig. $1 \mathrm{~J}$ max-corrected sensitivity \& specificity of BMI and WC to predict other CMM. Legend: cardio-metabolic risk marker (CMM), see other abbreviations in text 
Table 1 Cardio-metabolic risk markers (CMM) stratified by BMI $\left(\mathrm{kg} / \mathrm{m}^{2}\right)$ categories

\begin{tabular}{|c|c|c|c|c|c|c|c|}
\hline \multirow[t]{2}{*}{$\mathrm{CMM}^{\mathrm{a}}$} & \multirow[t]{2}{*}{$<18.5$} & \multirow[t]{2}{*}{18.5 to $<24.9$} & \multirow[t]{2}{*}{25.0 to 29.9} & \multirow[t]{2}{*}{$\geq 30.0$} & \multicolumn{3}{|l|}{$R^{2}$} \\
\hline & & & & & Linear & Other $^{b}$ & Type $^{b}$ \\
\hline BMl & $17.4 \pm 0.8$ & $21.8 \pm 1.8$ & $26.9 \pm 1.4$ & $34.9 \pm 5.3$ & & & \\
\hline WC & $62.5 \pm 4.8$ & $70.7 \pm 6.3$ & $82.0 \pm 7.5$ & $96.5 \pm 10.7$ & 0.69 & 0.81 & B \\
\hline SBP & $105.0 \pm 11.0$ & $110.0 \pm 14.0$ & $117.0 \pm 11.0$ & $120.0 \pm 16.0$ & 0.13 & 0.18 & A \\
\hline DBP & $69.0 \pm 9.0$ & $72.0 \pm 9.0$ & $76.0 \pm 11.0$ & $79.0 \pm 11.0$ & 0.11 & 0.14 & A \\
\hline $\mathrm{HDL}-\mathrm{C}$ & $46.9 \pm 8.7$ & $45.2 \pm 9.1$ & $42.4 \pm 8.9$ & $37.9 \pm 11.3$ & 0.08 & 0.17 & B \\
\hline LDL-C & $80.4 \pm 21.1$ & $98.2 \pm 28.3$ & $98.5 \pm 25.2$ & $111.2 \pm 37.9$ & 0.10 & 0.12 & A \\
\hline Non HDL-C & $95.9 \pm 22.8$ & $115.3 \pm 30.9$ & $116.1 \pm 29.4$ & $138.0 \pm 43.2$ & 0.14 & 0.17 & B \\
\hline TC & $142.8 \pm 25.6$ & $160.5 \pm 31.1$ & $158.6 \pm 28.2$ & $175.9 \pm 41.5$ & 0.09 & 0.11 & $D$ \\
\hline $\mathrm{TC} / \mathrm{HDL}-\mathrm{C}$ & $3.1 \pm 0.6$ & $3.7 \pm 1.0$ & $3.9 \pm 1.0$ & $5.1 \pm 2.3$ & 0.16 & 0.22 & $D$ \\
\hline TAG & $77.0 \pm 24.0$ & $87.5 \pm 42.9$ & $98.2 \pm 37.8$ & $144.9 \pm 96.0$ & 0.11 & 0.14 & $A$ \\
\hline TAG/HDL-C & $1.7 \pm 0.7$ & $2.1 \pm 1.4$ & $2.5 \pm 1.3$ & $4.9 \pm 6.1$ & 0.07 & 0.17 & $\mathrm{D}$ \\
\hline FG & $77.1 \pm 9.0$ & $77.4 \pm 8.1$ & $81.2 \pm 10.7$ & $82.0 \pm 12.2$ & 0.04 & 0.50 & A \\
\hline $\mathrm{Fl}$ & $9.0 \pm 7.7$ & $10.0 \pm 5.6$ & $13.9 \pm 12.3$ & $20.8 \pm 11.6$ & 0.17 & 0.27 & $C$ \\
\hline HOMA-IR & $1.8 \pm 1.6$ & $2.0 \pm 1.2$ & $2.9 \pm 2.9$ & $4.3 \pm 2.6$ & 0.14 & 0.25 & $\mathrm{D}$ \\
\hline QUICKI & $0.37 \pm 0.03$ & $0.36 \pm .03$ & $0.34 \pm 0.03$ & $0.32 \pm 0.02$ & 0.23 & 0.26 & A \\
\hline UA & $4.4 \pm 1.0$ & $4.9 \pm 1.0$ & $5.3 \pm 1.3$ & $6.0 \pm 1.5$ & 0.12 & 0.20 & $B$ \\
\hline
\end{tabular}

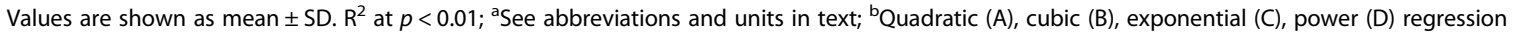

CMM in obese and overweight subjects respectively (Table 2), showed the strongest linear $\left(R^{2}=0.69\right)$ or cubic $\left(\mathrm{R}^{2}=0.81\right)$ relationship with BMI. FG $(1-5 \%)$, TC and UA (3-20\%) were the less prevalent CMM across BMI categories. Quadratic regression did not improve the linear trend between BMI and most CMM, while power (Log-Log) regression improved that of HOMA-IR,

Table 2 Prevalence (\%) of altered CMM by BMI $\left(\mathrm{kg} / \mathrm{m}^{2}\right)$

\begin{tabular}{lllllll} 
category & \multicolumn{7}{l}{ CMM ${ }^{a}$} & $<18.5$ & 18.5 to $<24.9$ & 25.0 to 29.9 & $\geq 30.0$ & $\Delta_{\text {N-OW }}$ & $\Delta_{\text {OW-OB }}$ \\
\hline WC & 0 & 1 & 39 & 92 & 38 & 53 \\
HTA & 7 & 8 & 28 & 39 & 20 & 11 \\
HDL-C $(\downarrow)$ & 44 & 42 & 66 & 71 & 24 & 5 \\
LDL-C & 13 & 47 & 41 & 58 & 6 & 11 \\
TC & 3 & 5 & 9 & 20 & 4 & 11 \\
TAG & 1 & 7 & 13 & 31 & 6 & 18 \\
TAG/HDL-C & 7 & 21 & 28 & 47 & 7 & 19 \\
FG & 1 & 1 & 3 & 5 & 2 & 2 \\
FI ( $)$ & 16 & 18 & 43 & 81 & 25 & 38 \\
HOMA-IR & 13 & 17 & 35 & 75 & 18 & 40 \\
QUICKI $(\downarrow)$ & 10 & 15 & 31 & 75 & 16 & 44 \\
HTGW & 0 & 0 & 9 & 30 & 9 & 21 \\
UA & 0 & 1 & 4 & 20 & 3 & 16 \\
MetS & 0 & 0 & 16 & 42 & 16 & 26 \\
\hline P-trend & 0.01 & See &
\end{tabular}

P-trend $<0.01$; ${ }^{\mathrm{a}}$ See abbreviations and units in text; otherwise indicated, a higher CMM value (than cut off point) was considered altered. Increment $(\Delta)$ from normal-overweight ( $\mathrm{N}-\mathrm{OW}$ ), from overweight-obesity (OW-OB)
TC/HDL-C and TG/HDL-C. Except for WC (81 \%), BMI explained 4 to $50 \%$ of the associated variance to all other CMM, regardless of the goodness-of-fit model.

Both, prevalence (Table 2) and incidence (Table 3) of abnormal CMM increased across BMI categories $(p \leq 0.01)$. However, increments $(\Delta)$ in lipid-related CMM, UA, FG and HTGW were low between normal to overweight $\left(\Delta_{\mathrm{N}-\mathrm{OW}}\right)$. However, except for TC, HDL-C, LDL-C, HTA and FG (+2-11\%), huge increments $(+16-53 \%)$ in all other CMM were observed from overweight to obesity $\left(\Delta_{\text {Ow-OB }}\right)$. The five most prevalent $(\geq 71 \%)$ CMM in obese subjects were high WC, FI, HOMA-IR, QUICKI and HDL-C while the less prevalent was FG (5\%). An additional 21, 26 and $40 \%$ subjects with HTGW, MetS and IR, respectively, increased from overweight to obesity. Also, 74-75 \% under- or normal weight subjects had 1-2 altered CMM, 58 \% overweight subjects had 3-6 altered CMM, and 54 \% obese subjects had 6-8 altered CMM.

Reliability [sensitivity (Se, low false negatives) + specificity (Sp, low false positives)] of both BMI cutoffs (25 and $30 \mathrm{~kg} / \mathrm{m}^{2}$ ) to predict WC changes did not vary much: [Youden's Index (J), 68 to 74] reaching $97 \%$ (Se) and $71 \%$ (Sp) in obese subjects (Table 4). However, changing the BMI from 25 to $30 \mathrm{~kg} / \mathrm{m}^{2}$ decreased Se but increased Sp to the same extent ( $24 \%$ in average) when predicting other CMM. With a BMI $=30 \mathrm{~kg} / \mathrm{m}^{2}$, the lowest and highest Se was observed for HDL-C and LDL-C (33-34 \%) and UA and HTGW (79\%), respectively while its Sp was for WC and FG (71-75\%) and HOMA-IR/FI/QUICKI (90-91\%). WCF showed practically the same prediction 
Table 3 Incidence (\%) of altered CMM by BMI $\left(\mathrm{kg} / \mathrm{m}^{2}\right)$ category

\begin{tabular}{llllr}
\hline$\#$ & $<18.5$ & 18.5 to $<24.9$ & 25.0 to 29.9 & $\geq 30.0$ \\
\hline 1 & 35.2 & 26.3 & 7 & 3.9 \\
2 & 39.4 & 28.9 & 14.1 & 5.2 \\
3 & 9.9 & 18.4 & 26.8 & 5.2 \\
4 & 11.3 & 9.2 & 9.9 & 7.8 \\
5 & 1.4 & 5.3 & 5.6 & 9.1 \\
6 & 1.4 & 3.9 & 15.5 & 22.1 \\
7 & 1.4 & 5.3 & 8.5 & 16.9 \\
8 & & 2.7 & 8.5 & 15.3 \\
9 & & & 4.1 & 6.7 \\
$\geq 10$ & & & & 7.8 \\
\hline
\end{tabular}

Number of altered CMM (\#)

power like WCM (same Se and Sp) toward the same CMM: Lowest (HDL-C and LDL-C) and highest (UA, HTGW, MetS) Se, lowest (TC) and highest (FI, HOMAIR, QUICKI) Sp. J ranged from $16 \%$ (HDL-C and LDL-C) to $68 \%$ (WC) for BMI $\left(30 \mathrm{~kg} / \mathrm{m}^{2}\right)$, from $14 \%$ (LDL-C) to $74 \%$ (MetS) for WCF and from $23 \%$ (LDL-C) to $78 \%$ (HTGW) for WCM.

When plotting the most reliable Se \& Sp (that is, those obtained at $\max$ ), it was possible to graphically identify the best predicted CMM by BMI (up), WCM (center) and WCF (down), as the closest CMM located at the upper right corner of each graph (Fig. 1). As expected, BMI was a strong predictor of WC $(\max =68-74 \%)$

Table 4 Se, Sp and Youden's Index ( $)$ of BMI \& WC to detect other CMM abnormalities

\begin{tabular}{|c|c|c|c|c|c|c|c|c|c|c|c|c|}
\hline \multirow[t]{3}{*}{$\mathrm{CMM}^{\mathrm{a}, \mathrm{b}}$} & \multicolumn{6}{|c|}{$\mathrm{BMI}\left(\mathrm{kg} / \mathrm{m}^{2}\right)$} & \multicolumn{6}{|c|}{$\mathrm{WC}(\mathrm{cm})$} \\
\hline & \multicolumn{3}{|l|}{25} & \multicolumn{3}{|l|}{30} & \multicolumn{3}{|l|}{ WCF } & \multicolumn{3}{|c|}{ WCM } \\
\hline & $\mathrm{Se}$ & $S p$ & J & $\mathrm{Se}$ & $\mathrm{Sp}$ & J & $\mathrm{Se}$ & $\mathrm{Sp}$ & J & $\mathrm{Se}$ & Sp & $J$ \\
\hline 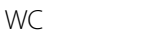 & 99 & 75 & 74 & 97 & 71 & 68 & & & & & & \\
\hline TA & 82 & 58 & 40 & 49 & 80 & 29 & 71 & 69 & 40 & 57 & 78 & 35 \\
\hline DL- & 62 & 65 & 27 & 33 & 83 & 16 & 43 & 81 & 24 & 52 & 82 & 34 \\
\hline DL-C & 62 & 58 & 20 & 34 & 82 & 16 & 45 & 69 & 14 & 45 & 78 & 23 \\
\hline & 78 & 53 & 31 & 56 & 77 & 33 & 58 & 67 & 25 & 67 & 71 & 38 \\
\hline$A G$ & 85 & 55 & 40 & 62 & 79 & 41 & 90 & 68 & 58 & 69 & 76 & 45 \\
\hline AG/HDL-C & 74 & 59 & 33 & 50 & 83 & 33 & 53 & 71 & 24 & 64 & 80 & 44 \\
\hline$G$ & 75 & 51 & 26 & 50 & 75 & 25 & 75 & 64 & 39 & 75 & 68 & 43 \\
\hline$(\uparrow)$ & 13 & 69 & 48 & 53 & 91 & 44 & 0 & 80 & 44 & 58 & 88 & 46 \\
\hline OMA-IR & 79 & 65 & 44 & 55 & 90 & 45 & 69 & 79 & 48 & 58 & 85 & 43 \\
\hline UIC & 82 & 65 & 47 & 59 & 90 & 49 & 67 & 79 & 46 & 65 & 85 & 50 \\
\hline HTGW & 100 & 55 & 55 & 79 & 80 & 59 & 100 & 69 & 69 & 100 & 78 & 78 \\
\hline A & 95 & 53 & 48 & 79 & 78 & 57 & 100 & 68 & 68 & 77 & 73 & 50 \\
\hline MetS & 100 & 58 & 58 & 74 & 82 & 56 & 100 & 74 & 74 & 93 & 82 & 75 \\
\hline
\end{tabular}

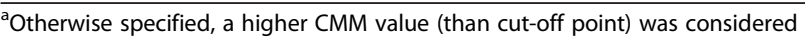
at risk for CMD, sensitivity (Se, \%), specificity (Sp, \%). $J=$ Se (\%) + Sp (\%) - 100 [25], ${ }^{\text {b }}$ See text for abbreviations and units and to a lesser extent of HTGW, UA and MetS (Jmax = 48-59 \%). WCM predicted in strong manner HTGW, MetS, UA and QUICKI ( $\max =50-78 \%$ ) while WCF predicted MetS, HTGW, and UA ( $\max =68-74 \%)$. The less reliable prediction at Jmax was as follows: HDL-C \& LDL-C, $\quad(\max =14-34 \quad \% ; \quad \mathrm{BMI} / \mathrm{WCF} /$ WCM $)$, TC $(\max =31-38 \%, \mathrm{BMI} / \mathrm{WCM} / \mathrm{WCF})$, and FG $(\max =25-43 \%$, BMI/WCF/BMI). Lastly, specific $\mathrm{BMI}$ and WC cutoffs to predict other CMM with the highest reliability (at Jmax) are depicted in Fig. 1. Lastly, standard cutoffs for Mexican adults (bold) differed from those obtained at Jmax [specific (grey squares), CI95 \% $(\leftrightarrow)$ ]: Distribution of most CMM was moderate-highly reliable at $27 \pm 3 \mathrm{~kg} / \mathrm{m}^{2}$ (CI $\left.95 \%, 25-28\right), 85 \pm 5 \mathrm{~cm}$ (CI $95 \%, 82-88)$ and $81 \pm 6 \mathrm{~cm}$ (CI $95 \%, 75-87$ ), for BMI, WCM and WCF, respectively (Fig. 2).

\section{Discussion}

Overweight and obesity in young Mexicans has reached epidemic proportions. According to the 2012 National Health \& Nutrition Survey [32], four (17-19 y) and five $(20-29$ y) out of ten young Mexicans have a BMI $\geq 25 \mathrm{~kg} /$ $\mathrm{m}^{2}$, most of them bearing a morbid WC. BMI and WC have increased overtime in Mexicans [33] as a consequence of lifestyle changes (e.g. low physical activity and unhealthy dietary habits); however, as compared to BMI, WC has increased disproportionately from 1999 to 2012, particularly in young (20-29 y) woman (WCF: $+6.6 \mathrm{~cm}, p$ $<0.0001)$ [34]. The National Agreement for Nutritional Health (ANSA) and other public policies aimed to prevent and control obesity, should be strengthened and improved urgently since there is no evidence to infer that this trend will decrease in the near future $[1,23,33]$, particularly if intervention \& surveillance programs are not properly designed, implemented and evaluated. About this, BMI and WC cutoffs established by international organizations (e.g. WHO or NHBLI) are often used to evaluate not only their secular trends but also as surrogate measures to evaluate CMD risk. However, BMI and WC cutoffs are influenced by ethnicity, gender, age and the presence of co-morbidities $[9,18,35,36]$, so age-specific cutoffs to evaluate intervention programs in Mexico should be carefully selected [23-25].

A BMI $\geq 25 \mathrm{~kg} / \mathrm{m}^{2}$ is associated with greater odds of CMM abnormalities, MetS, IR, HTN, and T2DM [2, 11, 12]. That is why many of studies published in the last ten years have been focused not only on CMM's epidemiology but also on the specific clustering patterns of BMI with other CMM [35, 36]. However, very few have explored the prevalence or incidence of CMM along the BMI range, particularly in Mexican youth [19]. This study shows that, with few exemptions (e.g. FG), the magnitude, prevalence and incidence of any CMM increase across BMI categories $(p \leq 0.01)$, with huge increments between 25 and 30 

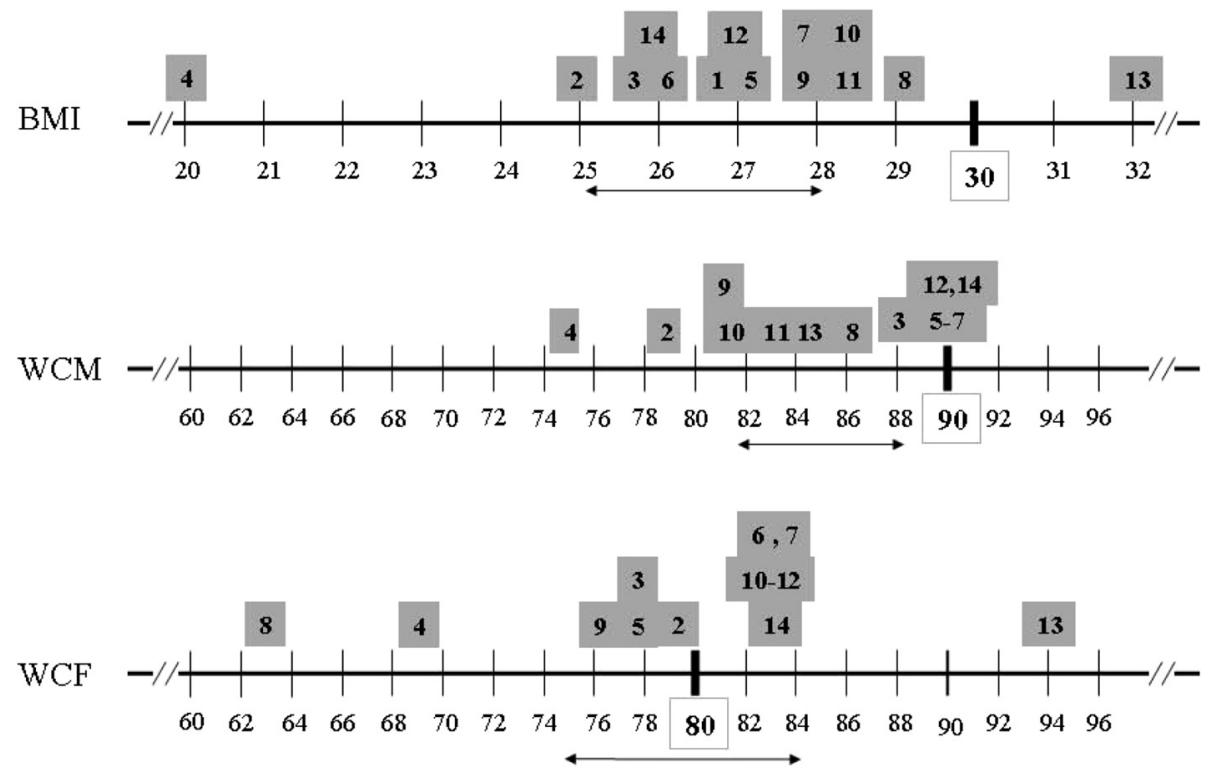

Fig. 2 CMM distribution along BMI and WC range 1 . Legend: ${ }^{1} \mathrm{Jmax}$-corrected cutoffs; Conventional BMI and WC (WCM/WCF) Cutoff values (bold), Jmax-derived cutoff values to predict individual (grey square) and Cl $95 \%(\leftrightarrow)$ CMM; cardio-metabolic risk markers (CMM): WC (1), HTA (2), HDL-C (3), LDL-C (4), TC (5), TAG (6), TAG/HDL-C (7), FG (8), FI (9), HOMA-IR (10), QUICKI (11), HTGW (12), UA (13), MetS (14)

$\mathrm{kg} / \mathrm{m}^{2}$. This behavior is supported by the fact that, in many cases, the mathematical relationship between BMI and each CMM improved with a nonlinear goodness-offit. The five most prevalent $(\geq 71 \%)$ CMM in obese subjects were high WC, HDL-C and three insulin-related CMM. Also, $16 \%$ (overweighed) and $42 \%$ (obese) subjects presented $\geq 3$ MetS traits, and an additional 21, 26 and $40 \%$ subjects with CMM-clustered phenotypes (HTGW, MetS and IR, respectively) were added from overweight to obesity. Based on these results, BMI is still valuable for the primary screening of CMD in school health programs such as Healthy University [28]. Many cross-sectional studies also support the usefulness of BMI for CMD screening [35-37], but also support the idea that $\mathrm{BMI}$ is an even better predictor if it is co-assayed or clustered with other anthropometric [e.g. WC, fat (FMI) and lean body mass index (LBMI)] or biochemical (e.g. such as TAG or HDL-C) CMM, either as simple risk scores (ratios) or in prospective equations. In our case, the study of novel associations between BMI (or WC) with the observed low prevalent (e.g. FG) or mild-BMI sensitive (e.g. TC, HDL-C) CMM, deserves further investigations.

However, despite the fact that $74-75 \%$ subjects with a BMI $<25 \mathrm{~kg} / \mathrm{m}^{2}$ only had 1 or 2 altered CMM, $\sim 46 \%$ lean $(18.5$ to $<24.9 \mathrm{~kg} / \mathrm{m} 2)$ subjects were dyslipidemic ( $\uparrow \mathrm{LDL}-$ C, TAG/HDL-C; $\downarrow$ HDL-C) while $\sim 17 \%$ were insulinresistant ( $\uparrow F \mathrm{~F}, \uparrow$ HOMA-IR). This "silent" phenomenon has several causes including the Mexican's genetic predisposition to dyslipidemias [38] and T2DM [39], or the higher prevalence of snacking [40] and intake of junk food [41] that is quite popular in this population segment.
However, these findings also indicate that weight gain itself do not impose a concurrent CMD risk in younger people from northern Mexico. In the OPUS PRIME study [35] the relative frequency of nine phenotypes [36 \% lean, $43 \%$ overweighed, and $21 \%$ obese Mexican adults clustered in three CMM profiles (MetS traits): normometabolic (none), intermediate (1-2) and dysmetabolic $(\geq 3)$ ] was evaluated; the study showed that only $27 \%$ lean subjects were normo-metabolic, while only $37 \%$ of obese individuals were dysmetabolic. Murguía-Romero et al. [19] also reported from a national representative study with 3176 young (17-24 y) that all BMI strata included a MetS prevalence greater than zero (5.7 \% lean, $21.8 \%$ overweighed, and $48.6 \%$ obese), implying once again that weight gain is not a mandatory factor for MetS.

WC is a crude estimate of abdominal fat accumulation and its measurement provides additional information on CMD risk at any given BMI value. As compared to BMI, $\mathrm{WC}$ is a better predictor of certain dysmetabolic processes such as inflammation, dyslipidemias and non-insulin dependent diabetes mellitus [8-11, 20]. Here, conventional WC cutoffs for Mexican adults (WCM/WCF) were moderate reliable $(J=69-78)$ to predict MetS and HTGW (both including a high WC in their definition) and UA in women $(J=68)$. In a previous study we have reported the excellent reliability of HTGW as surrogate measure for MetS in young Mexicans [8], since it is related to a higher weight, BMI, FG, TC, BP and to lower levels of HDL-C, which in turn are associated to a higher risk for HTN and IR. So, the binary association implied in HTGW (high TAG, high WC) normalizes WC to increase its Se and Sp to predict 
other CMM. Since young overweighed and obese individuals with a lower fat mass are more prone to IR than sex- and BMI-matched adults [42], the specific relationship between WC and truncal body fat distribution should be evaluated in future studies. Also, hyperuricemia (UA) is an independent factor associated with MetS and hypertrigliceridemia [31], HTA, IR, fatty liver and chronic kidney diseases [43]. To our knowledge, this is the first report on the association of WC with UA in young Mexicans.

However, WC had a very low predictive value toward lipid related-CMMs $(J=14-58)$. This could be related to several metabolic factors such as the high hemodynamics of cholesterol or the adipocyte's TAG turnover rate, both influenced by age and BMI status [44-47], although it could also be related to the small number of participants in this study. Nevertheless, WC was the most prevalent CMM in obese subjects and BMI explained almost all (81 \%) of its associated variance with an excellent reliability $(\max =86 \%)$, which is consistent with other studies in young populations [48]. Under the caution that deserves the comparison due the small population sample, the prevalence of all CMM and their relationship with WC and BMI increments largely coincide with other crosssectional studies in young Mexicans from central $[8,14]$ and northern Mexico [49].

Also, by using a very simple statistical tool (Youden's index, J), the most reliable (Jmax) cutoff for BMI, WCM and WCF to predict other CMM was obtained. Other studies have also documented the increase in the reliability of several obesity indexes to predict cardiometabolic risk in pediatric populations, when their standard cutoffs have been corrected at $J \max [37,50]$. Here, most CMM abnormalities started at a lower BMI $(27 \pm 3 \mathrm{~kg} /$ $\left.\mathrm{m}^{2}\right)$ and WCM $(80 \pm 8 \mathrm{~cm})$ but almost same the WCF $(85 \pm 5 \mathrm{~cm})$ than those proposed by WHO, as previously found in the 2000 (ENSA) and 2006 (ENSANUT) Mexican health surveys [25]. Strikingly, certain CMM reach their highest prediction at BMI and WC cutoffs out of their CI $95 \%$ range (e.g. UA at $\mathrm{WCF}=94 \mathrm{~cm}$ ). However, it should be noted that enhancing Se and Sp to achieve Jmax of any CMM increases its likelihood ratio and odds ratio but do not minimize the epidemiological value of conventional cutoffs, it just informs about the possible "lost cases".

\section{Stregths \& limitations}

The authors recognize that this study has certain strengths and limitations. The experimental design and sampling strategy allowed a reasonable comparison (same "n") of the effects of weight gain and central obesity and several metabolic derangements (CMM) in a same study, and even when not intended to make inferences about the original universe, the behavior of this sample was quite similar to our previous study [8]. In addition, the assessment of certain CMM not previously reported in other studies of the same nature (e.g. UA), further contributes to the generation of knowledge in this field. However, its cross-sectional nature does not allow inferences on the current relationship of any CMM with a future risk for CMD. In addition, the sample size could result in no statistical significance for certain CMM with expected biological deviations. Nevertheless, our study could be considered as a "pilot" study, contributing to the design of more extensive cross-sectional or longitudinal studies.

\section{Conclusions}

BMI and WC are good predictors of several CMM in the studied population, although at different cutoffs than current reference values. This study enables us to argue on the importance of the systematic measurement of WC and BMI, and possibly TAG, to follow the secular changes in CMD risk among college students.

\section{Ethics \& consent statement}

All participants signed an informed consent after explaining the nature, objectives and risks inherent to the study (when the participant was under $18 \mathrm{y}$, its parent/guardian signed the informed consent and the participant accepted to participate). Data confidentiality was protected as stipulated by the Mexican Statistical and Geographical information Law, and the study protocol met the standards of the Helsinki Declaration and was approved by UACJ ethics committee [8].

\section{Abbreviations \\ ANSA: National agreement for nutritional health; BMI: body mass index; BP: blood pressure; CMD: cardiometabolic disease; CMM: cardiometabolic risk marker; CVD: cardiovascular disease; DBP: diastolic BP; DEXA: dual x-ray absor- tiometry; FG: fasting glucose; Fl: fasting insulin; HDL-C: high-density lipoprotein cholesterol; HOMA: homeostatic model assessment; HTA: hypertension; HTGW: hypertriglyceridemic-high waist phenotype; IR: insulin resistance; ISAK: International Society for the advancement of kinanthropometry; J, Jmax: Youden index; LDL-C: low-density lipoprotein cholesterol; MetS: metabolic syndrome; OB: obesity; OW: overweight; QUICKI: quantitative insulin check index; SBP: systolic BP; Se: sensitivity; Sp: specificity; T2DM: type 2 diabetes mellitus; TAG: triacylglycerides; TC: total cholesterol; UA: high uric acid; WC: waist circumference; WCF: waist circumference of female; WCM: waist circumference of male.}

Competing interests

All authors declare no actual or potential conflict of interest.

\section{Authors' contributions}

AWM, ARJ and RVM conceived the general study, participatd in data gathering \& statistical analysis and wrote, revised and approved and final version of this manuscript. RPHT, DCTP, JRJF, ARMC, MMR, IAGO and RUR participated in laboratory logistics, biological sample collection, anthropometry, and were involved in drafting the manuscript. All authors gave their final approval of the final version of this manuscript and are accountable for all aspects of the work. 


\section{Acknowledgements}

This study was performed under the collaboration agreement between UAC and UNAM (UACJ/AG/CV-22/2015 and No. Registro UNAM: 41079-789-7-IV-15). All authors are indebted to Universidad Saludable (UACJ) and Grupo Diagnóstico Médico PROA, SA de CV (UNAM). Supported in part by FESI-DIP-PAPCA2014-53, UNAM. RVM was a visiting Professor at UACJ (supported in part by PASPA, DGAPA, UNAM)

\section{Author details}

'Instituto de Ciencias Biomédicas, Universidad Autónoma de Ciudad Juárez, Anillo Envolvente del Pronaf y Estocolmo, Ciudad Juárez 32300, Chihuahua, México. ${ }^{2}$ Facultad de Ciencias de la Cultura Física, Universidad Autónoma de Chihuahua, Chihuahua, México. ${ }^{3}$ Unidad de Biomedicina, Universidad Nacional Autónoma de México, Tlalnepantla, México. ${ }^{4}$ Laboratorio Nacional en Salud: Diagnóstico Molecular y Efecto Ambiental en Enfermedades Crónico-Degenerativas, Facultad de Estudios Superiores Iztacala, Universidad Nacional Autónoma de México, Tlalnepantla, México.

\section{Received: 30 November 2015 Accepted: 19 February 2016 Published online: 08 March 2016}

\section{References}

1. Stevens G, Dias RH, Thomas KJ, Rivera JA, Carvalho N, Barquera S, Hill K, Ezzati M. Characterizing the epidemiological transition in Mexico: national and subnational burden of diseases, injuries, and risk factors. PLoS Med. 2008:5(6):e125.

2. Global burden of metabolic risk factors for chronic diseases collaboration. Cardiovascular disease, chronic kidney disease, and diabetes mortality burden of cardio metabolic risk factors from 1980 to 2010: a comparative risk assessment. Lancet Diabetes Endocrinol. 2014;2(8):634-47.

3. Arredondo A, Aviles R. Costs and epidemiological changes of chronic diseases: implications and challenges for health systems. PLoS One. 2015;10(3):e0118611

4. Beltrán-Sánchez H, Drumond-Andrade FC, Riosmena F. Contribution of socioeconomic factors and health care access to the awareness and treatment of diabetes and hypertension among older Mexican adults. Salud Pub Mex. 2015;57 suppl 1:S6-S14.

5. Juárez-Ramírez C, Márquez-Serrano M, de Snyder Salgado N, PelcastreVillafuerte BE, Ruelas-González MG, Reyes-Morales $\mathrm{H}$. Health inequality among vulnerable groups in Mexico: older adults, indigenous people, and migrants. Rev Panam Salud Pub. 2014;35(4):284-90.

6. Aguilar-Salinas CA. Non communicable chronic diseases, the main health problem in Mexico. Salud Pub Mex. 2013;55:S347-50.

7. Rojas-Martínez R, Aguilar-Salinas CA, Jiménez-Corona A, Gómez-Pérez FJ, Barquera S, Lazcano-Ponce E. Prevalence of obesity and metabolic syndrome components in Mexican adults without type 2 diabetes or hypertension. Salud Pub Mex. 2012;54(1):7-12.

8. Villalobos-Molina R, Wall-Medrano A, Rodríguez-Tadeo A, Urquídez-Romero R, Hernández-Torres RP, Murguía-Romero M, et al. HypertriglyceridemicWaist (HTGW) phenotype in university students from two regions of México. Acta Med Mediterranea. 2015;31:173-7.

9. Macias N, Quezada AD, Flores M, Valencia ME, Denova-Gutiérrez E, QuiterioTrenado $\mathrm{M}$, et al. Accuracy of body fat percent and adiposity indicators cut off values to detect metabolic risk factors in a sample of Mexican adults. BMC Pub Health. 2014;14(1):341.

10. Wei M, Gaskill SP, Haffner SM, Stern MP. Waist circumference as the best predictor of noninsulin dependent diabetes mellitus (NIDDM) compared to body mass index, waist/hip ratio and other anthropometric measurements in Mexican Americans-a 7-year prospective study. Obes Res. 1997;5(1):16-23.

11. Klein S, Allison DB, Heymsfield SB, Kelley DE, Leibel RL, Nonas C, Kahn R. Waist circumference and cardiometabolic risk: a consensus statement from shaping America's health: Association for Weight Management and Obesity Prevention; NAASO, the Obesity Society; the American Society for Nutrition; and the American Diabetes Association. Obesity. 2007;15(5):1061-7.

12. Murguía-Romero M, Jiménez-Flores JR, Sigrist-Flores SC, Méndez-Cruz AR, Villalobos-Molina R. Insulin and HOMA-IR in healthy young Mexicans: a cut off proposal. Internal Medicine Open Access. 2014;S6:001.

13. Katz A, Nambi SS, Mather K, Baron AD, Follmann DA, Sullivan G, Quon MJ. Quantitative insulin sensitivity check index: a simple, accurate method for assessing insulin sensitivity in humans. J Clin Endocrinol Metab. 2000;85(7):2402-10.
14. Murguía-Romero M, Jiménez-Flores JR, Sigrist-Flores SC, Tapia-Pancardo DC, Jiménez-Ramos A, Méndez-Cruz AR, et al. Prevalence of metabolic syndrome in young Mexicans: A sensitivity analysis on its components. Nutr Hosp. 2015;32(1):189-95.

15. Murguía-Romero M, Jiménez-Flores JR, Sigrist-Flores CS, Espinoza-Camacho MA, Jiménez-Morales M, Piña E, Méndez-Cruz AR, Villalobos-Molina R, Reaven GM. Plasma triglyceride/HDL-cholesterol ratio, insulin resistance, and cardiometabolic risk in young adults. J Lipid Res. 2013;54:2795-9.

16. Esteghamati A, Ashraf H, Khalilzadeh O, Zandieh A, Nakhjavani M, Rashidi A, Haghazali M, Asgari F. Optimal cut-off of homeostasis model assessment of insulin resistance (HOMA-IR) for the diagnosis of metabolic syndrome: third national surveillance of risk factors of non-communicable diseases in Iran (SuRFNCD-2007). Nutr Metab (Lond). 2010;7(26):2-8.

17. Expert Panel on Detection, Evaluation, and Treatment of High Blood Cholesterol in Adults (Adult Treatment Panel III). Executive Summary of the Third Report of the National Cholesterol Education Program (NCEP). JAMA. 2001:285:2486-97.

18. Grundy SM, Cleeman JI, Merz CNB, Brewer HB, Clark LT, Hunninghake DB, Pasternak RC, Smith SC, Stone NJ. For the Coordinating Committee of the National Cholesterol Education Program. Implications of recent clinical trials for the national cholesterol education program adult treatment panel III guidelines. J Am Coll Cardiol. 2004;44(3):720-32.

19. Murguía-Romero M, Jiménez-Flores R, Villalobos-Molina R, Méndez-Cruz AR. Estimating the geographical distribution of the prevalence of the metabolic syndrome in young Mexicans. Geospat Health. 2012;6(3):43-50.

20. da Rocha ALC, Pereira PF, Pessoa MC, Alfenas RDCG, Segheto W, da Silva DCG, Pacheco de Andrade M, Longo GZ. Hypertriglyceridemic waist phenotype and cardiometabolic alterations in Brazilian adults. Nutr Hosp. 2015;32(3):1099-106.

21. Pedroza-Tobias A, Trejo-Valdivia B, Sanchez-Romero LM, Barquera S. Classification of metabolic syndrome according to lipid alterations: analysis from the Mexican National Health and Nutrition Survey 2006. BMC Pub Health. 2014;14(1):1056.

22. Rojas R, Aguilar-Salinas CA, Jimenez-Corona A, Shamah-Levy T, Rauda J, et al. Metabolic syndrome in Mexican adults. Results from the National Health and Nutrition Survey 2006. Salud Pub Mex. 2010;52(Supl 1):S11-8.

23. Barquera S, Campos-Nonato I, Hernández-Barrera L, Pedroza A, RiveraDommarco JA. Prevalence of obesity in Mexican adults 2000-2012. Salud Pub Mex. 2013;55:S151-60.

24. Misra A, Wasir JS, Vikram NK. Waist circumference criteria for the diagnosis of abdominal obesity are not applicable uniformly to all populations and ethnic groups. Nutrition. 2005;21(9):969-76.

25. Sánchez-Castillo CP, Velázquez-Monroy O, Berber A, Lara-Esqueda A, Tapia-Conyer R, James WPT. Anthropometric cutoff points for predicting chronic diseases in the Mexican National Health Survey 2000. Obesity Res. 2003;11(3):442-51

26. Ruopp MD, Perkins NJ, Whitcomb BW, Schisterman EF. Youden index and optimal cut-off point estimated from observations affected by a lower limit of detection. Biometrical J. 2008:50(3):419-30.

27. Florath I, Brandt S, Weck MN, Moss A, Gottmann P, Rothenbacher D, Wabitsch M, Brenner $\mathrm{H}$. Evidence of inappropriate cardiovascular risk assessment in middle-age women based on recommended cut-points for waist circumference. Nutr Metab Cardiovasc Dis. 2014;24(10):1112-9.

28. Becerra HS. Universidades saludables: una apuesta a una formación integral del estudiante. Rev Psicol (PUCP). 2013;31(2):287-314 (in Spanish).

29. Friedewald WT, Levy RI, Fredrickson DS. Estimation of the concentration of low-density lipoprotein cholesterol in plasma, without use of the preparative ultracentrifuge. Clin Chem. 1972;18:499-502.

30. Alberti $\mathrm{KG}$, Eckel RH, Grundy SM, Zimmet PZ, Cleeman Jl, et al. Harmonizing the metabolic syndrome: a joint interim statement of the International Diabetes Federation Task Force on Epidemiology and Prevention; National Heart, Lung, and Blood Institute; American Heart Association; World Heart Federation; International Atherosclerosis Society; and International Association for the Study of Obesity. Circulation. 2009;120(16):1640-5.

31. Goncalves JP, Oliveira A, Severo M, Santos AC, López C. Cross-sectional and longitudinal associations between serum uric acid and metabolic syndrome Endocrine. 2012;41(3):450-7.

32. Gutiérrez JP, Rivera-Dommarco J, Shamah-Levy T, Villalpando-Hernández S, Franco A, Cuevas-Nasu L, Romero-Martínez M, Hernández-Ávila M. Encuesta Nacional de Salud y Nutrición 2012. Resultados Nacionales. México: Instituto Nacional de Salud Pública; 2012. Book in Spanish. 
33. Albrecht SS, Barquera S, Popkin BM. Exploring secular changes in the association between BMI and waist circumference in Mexican-origin and white women: A comparison of Mexico and the United States. Am J Human Biol. 2014;26(5):627-34.

34. Albrecht SS, Gordon-Larsen P, Stern D, Popkin BM. Is waist circumference per body mass index rising differentially across the United States, England, China and Mexico? Eur J Clin Nutr. 2015;69(12):1306-12. doi:10.1038/ejcn. 2015.71.

35. Fanghanel-Salmón G, Gutierrez-Salmeán G, Samaniego V, Meaney AM, Sanchez-Reyes L, Olivares-Corichi I, Najera N, Ceballos G, Meaney, E. Obesity phenotypes in urban middle-class cohorts; the PRIT-Lindavista merging evidence in Mexico: the OPUS PRIME study. Nutr Hosp. 2015;32(1):182-8.

36. Rao G, Powell-Wiley TM, Ancheta I, Hairston K, Kirley K, Lear SA, North KE, Palaniappan L, Rosal MS, American Heart Association Committee of the Council on Lifestyle and Cardiometabolic Health. Identification of obesity and cardiovascular risk in ethnically and racially diverse populations. A scientific statement from the American Heart Association. Circulation. 2015;132(5):457-72.

37. Weber DR, Leonard MB, Shults J, Zemel BS. A comparison of fat and lean body mass index to BMl for the identification of metabolic syndrome in children and adolescents. J Clin Endocrinol Metab. 2014;99(9):3208-16.

38. Pu J, Romanelli R, Zhao B, Azar KM, Hastings KG, Nimbal V, Fortmann SP, Palaniappan LP. Dyslipidemia in special ethnic populations. Cardiol Clin. 2015;33(2):325-33.

39. Méndez YL, Leal GR, González AS, Reyes VP, Ruvalcaba DR, Rangel GB. Variantes genotípicas del SNP-19 del gen de la CAPN 10 y su relación con la diabetes mellitus tipo 2 en una población de Ciudad Juárez. México Nutr Hosp. 2014;31(2):744-50. (in Spanish).

40. Duffey KJ, Rivera JA, Popkin BM. Snacking is prevalent in Mexico. J Nutr. 2014;144(11):1843-9.

41. Gómez-Miranda LM, Bacardí-Gascón M, Caravalí-Meza NY, Jiménez-Cruz A. Consumo de bebidas energéticas, alcohólicas y azucaradas en jóvenes universitarios de la frontera México-USA. Nutr Hosp. 2014;31(1):191-5.

42. Linder K, Springer F, Machann J, Fritsche A, Haring HU, Blumenstock G, et al. Relationships of body composition and liver fat content with insulin resistance in obesity-matched adolescents and adults. Obesity (Silver Spring). 2014;22(5):1325-133.

43. Johnson RJ. Why focus on uric acid? Curr Med Res Opin. 2015;31 suppl 2:3-7.

44. McNamara JR, Campos H, Ordovas JM, Peterson J, Wilson PW, Schaefer EJ. Effect of gender, age, and lipid status on low density lipoprotein sub fraction distribution. Results from the Framingham Offspring Study. Arterioscler Thromb Vasc Biol. 1987;7(5):483-90.

45. Mc Auley MT, Wilkinson DJ, Jones JJ, Kirkwood TB. A whole-body mathematical model of cholesterol metabolism and its age-associated dysregulation. BMC Systems Biol. 2012;6(1):130

46. Arner P, Bernard S, Salehpour M, Possnert G, Liebl J, Steier P, Spalding KL. Dynamics of human adipose lipid turnover in health and metabolic disease. Nature. 2011:478(7367):110-3.

47. Rydén M, Andersson DP, Bernard S, Spalding K, Arner P. Adipocyte triglyceride turnover and lipolysis in lean and overweight subjects. J Lipid Res. 2013:54(10):2909-13.

48. Pettitt DJ, Talton JW, Liese AD, Liu LL, Crimmins N, West NA, et al. Comparison of two waist circumference measurement protocols: the SEARCH for diabetes in youth study. Ped Obesity. 2012;7(6):e81-5.

49. Salas R, del Mar BM, Ramos E, Villarreal JZ, Pons A, Tur JA, Sureda A Metabolic syndrome prevalence among northern Mexican adult population. Plos One. 2014;9(8):e105581.

50. Bener A, Yousafzai MT, Darwish S, Al-Hamaq AO, Nasralla EA, Abdul-Ghani M. Obesity index that better predict metabolic syndrome: body mass index, waist circumference, waist hip ratio, or waist height ratio. J Obesity. 2013:2013:269038

\section{Submit your next manuscript to BioMed Central and we will help you at every step:}

- We accept pre-submission inquiries

- Our selector tool helps you to find the most relevant journal

- We provide round the clock customer support

- Convenient online submission

- Thorough peer review

- Inclusion in PubMed and all major indexing services

- Maximum visibility for your research

Submit your manuscript at www.biomedcentral.com/submit
C Biomed Central 